\title{
Calculation of Added Water Mass for 300t Fishery Administration Vessel
}

\author{
Caogen Xiong ${ }^{1, ~ a, ~ J i ~ W u ~}{ }^{1, b}$, Jun Long ${ }^{1, c}$ and Jinlong Bian ${ }^{2, d}$ \\ ${ }^{1}$ Dalian Scientific Test and Control Technology Institute, 16 Binhai Street. Dalian, 116013, China; \\ 2 Dalian Shipbuilding Industry Group Co, Ltd. Dalian, 116011, China. \\ axiongcaogen@163.com, ㄹmewuji@126.com, 'longjun3159@163.com, ddmubjl@163.com
}

Keywords: Fishery administration vessel, added water mass, vibration characteristics, 3 D modeling.

\begin{abstract}
To avoid resonance and make the 300t fishery administration vessel meet the requirements of low vibration and noise, vibration characteristics must be predicted during the process of design. In order to more accurately predict the vibration characteristics, it is necessary to calculate the added water mass. Three-dimensional modeling of the 300t fishery administration vessel is constructed accurately to calculate added water mass. Lewis formula is employed to obtain the added water mass. The added water mass of first three order vertical and horizontal vibration are calculated in this paper. Under the condition of no load, the added mass of vertical vibration is greater than horizontal vibration. Under the condition of full load, the added mass of horizontal vibration is greater.
\end{abstract}

\section{Introduction}

As a ship of marine fishery law enforcement and marine accident relief, fishery administration vessel need a better mobility and reliability characteristics. Because the fishery administration vessel need to work in different sea conditions, especially the extreme harsh sea conditions, and to ensure the reliability and comfort of the ship operation, it is necessary to suppress the hull vibration and reduce the noise at the beginning of the design. Because the ship added water mass and ship structure weight in an order of magnitude, the added water mass affects the natural frequency of the ship under various operating conditions. The inertia of ship added water mass has a greater impact on the hull vibration. In order to more accurately predict the vibration characteristics of the newly designed 300-ton fishery administration vessel, the calculation of the added water mass is carried out under no load and full load condition in this paper.

\section{Theoretical Analysis and Modeling}

\subsection{Calculation method of the added water mass.}

The empirical formula method, the fluid finite element method and boundary element method are the mainly calculation method of ship added water mass. Based on the actual ship test, F. M. Lewis, F. $H$. Todd etc. puts forward the empirical formula used to calculate added water mass. To calculate the added water mass, the empirical formula method of Lewis is adopted. To calculate the vertical vibration of the ship, the formula of added water mass on the unit length is:

$$
m_{a v}=\frac{1}{2} \pi a_{v} C_{v} K_{v i} \rho b^{2}
$$

Where $\alpha_{v}, C_{v}, K_{v i}, \rho$ and $b$ are shallow water correction factor, the correction factors of vertical vibration for added mass, three-dimensional flow correction factors of vertical vibration for added water, water density $\left(\mathrm{t} / \mathrm{m}^{3}\right)$ and the half width of the waterline in rated section $(\mathrm{m})$.

In calculating the horizontal vibration of the ship, the formula of added water mass on the unit length is:

$$
m_{a h}=\frac{1}{2} \pi a_{h} C_{h} K_{h i} \rho d^{2}
$$


Where $\alpha_{h}, C_{h}, K_{h i}, \rho$ and dare marrow water correction factor, the correction factors of horizontal vibration for added mass, three-dimensional flow correction factors of horizontal vibration for added water, water density $\left(\mathrm{t} / \mathrm{m}^{3}\right)$ and the sea gauge in rated section $(\mathrm{m})$.

Table 1. Three-dimensional flow correction coefficient Kvi and Khi

\begin{tabular}{cccccc}
\hline L/B or L/d & $\begin{array}{c}\text { 1st order } \\
(\mathrm{i}=1)\end{array}$ & $\begin{array}{c}\text { 2nd order } \\
(\mathrm{i}=2)\end{array}$ & $\begin{array}{c}\text { 3st order } \\
(\mathrm{i}=3)\end{array}$ & $\begin{array}{c}\text { 4th order } \\
(\mathrm{i}=4)\end{array}$ & $\begin{array}{c}\text { 5th order } \\
(\mathrm{i}=5)\end{array}$ \\
\hline 5.0 & 0.700 & 0.624 & 0.551 & 0.494 & 0.477 \\
6.0 & 0.748 & 0.678 & 0.614 & 0.560 & 0.515 \\
7.0 & 0.786 & 0.719 & 0.661 & 0.611 & 0.568 \\
8.0 & 0.815 & 0.756 & 0.698 & 0.653 & 0.611 \\
9.0 & 0.839 & 0.784 & 0.733 & 0.687 & 0.647 \\
10.0 & 0.858 & 0.808 & 0.759 & 0.716 & 0.677 \\
11.0 & 0.874 & 0.828 & 0.782 & 0.742 & 0.706 \\
12.0 & 0.888 & 0.845 & 0.802 & 0.763 & 0.730 \\
13.0 & 0.890 & 0.859 & 0.820 & 0.783 & 0.751 \\
14.0 & 0.909 & 0.870 & 0.835 & 0.803 & 0.770 \\
15.0 & 0.917 & 0.883 & 0.848 & 0.818 & 0.788 \\
20.0 & 0.947 & 0.920 & 0.895 & 0.876 & 0.857 \\
25.0 & 0.968 & 0.944 & 0.925 & 0.909 & 0.894 \\
30.0 & 0.980 & 0.958 & 0.940 & 0.924 & 0.910 \\
35.0 & 0.987 & 0.967 & 0.950 & 0.934 & 0.922 \\
\hline
\end{tabular}

Table 2. Added water mass coefficient $\mathrm{Cv}$ of vertical vibration

\begin{tabular}{ccccccccccc}
\hline $\begin{array}{c}\mathrm{b} / \mathrm{d} \\
\beta\end{array}$ & 0.2 & 0.4 & 0.6 & 0.8 & 1.0 & 1.2 & 1.4 & 1.6 & 1.8 & 2.0 \\
\hline 0.0 & 1.510 & 1.100 & 0.935 & 0.860 & 0.815 & 0.785 & 0.760 & 0.755 & 0.750 & 0.750 \\
0.1 & 1.250 & 0.975 & 0.860 & 0.800 & 0.775 & 0.765 & 0.755 & 0.752 & 0.753 & 0.753 \\
0.2 & 1.060 & 0.880 & 0.805 & 0.764 & 0.750 & 0.750 & 0.750 & 0.750 & 0.750 & 0.752 \\
0.3 & 0.815 & 0.815 & 0.760 & 0.750 & 0.750 & 0.755 & 0.760 & 0.770 & 0.775 & 0.790 \\
0.4 & 0.800 & 0.740 & 0.750 & 0.750 & 0.765 & 0.770 & 0.775 & 0.780 & 0.800 & 0.801 \\
0.5 & 0.740 & 0.760 & 0.765 & 0.774 & 0.785 & 0.790 & 0.800 & 0.816 & 0.825 & 0.831 \\
0.6 & 0.700 & 0.788 & 0.802 & 0.815 & 0.830 & 0.842 & 0.852 & 0.865 & 0.875 & 0.880 \\
0.7 & 0.860 & 0.880 & 0.895 & 0.905 & 0.915 & 0.920 & 0.925 & 0.933 & 0.940 & 0.942 \\
0.8 & 1.035 & 1.035 & 1.032 & 1.030 & 1.025 & 1.020 & 1.020 & 1.018 & 1.015 & 1.010 \\
0.9 & 1.320 & 1.270 & 1.240 & 1.200 & 1.185 & 1.162 & 1.150 & 1.130 & 1.120 & 1.115 \\
1.0 & 1.980 & 1.760 & 1.640 & 1.570 & 1.518 & 1.472 & 1.434 & 1.400 & 1.375 & 1.355 \\
\hline \multicolumn{8}{c}{ Table 3. Added water mass coefficient Ch of horizontal vibration } & & \\
\hline $\mathrm{b} / \mathrm{d} \beta$ & 0.2 & 0.4 & 0.6 & 0.8 & 1.0 & 1.2 & 1.4 & 1.6 & 1.8 & 2.0 \\
\hline 0.0 & 1.108 & 1.271 & 1.406 & 1.554 & 1.707 & 1.863 & 2.011 & 2.152 & 2.295 & 2.430 \\
0.1 & 1.083 & 1.197 & 1.327 & 1.440 & 1.554 & 1.678 & 1.791 & 1.912 & 2.036 & 2.134 \\
0.2 & 1.061 & 1.160 & 1.270 & 1.352 & 1.431 & 1.530 & 1.606 & 1.683 & 1.764 & 1.851 \\
0.3 & 1.049 & 1.123 & 1.184 & 1.263 & 1.308 & 1.387 & 1.436 & 1.505 & 1.554 & 1.616 \\
0.4 & 1.024 & 1.073 & 1.123 & 1.172 & 1.209 & 1.263 & 1.295 & 1.332 & 1.382 & 1.419 \\
0.5 & 1.017 & 1.049 & 1.061 & 1.091 & 1.123 & 1.147 & 1.172 & 1.191 & 1.221 & 1.246 \\
0.6 & 1.012 & 1.024 & 1.036 & 1.061 & 1.061 & 1.073 & 1.086 & 1.086 & 1.098 & 1.110 \\
0.7 & 1.007 & 1.012 & 1.012 & 1.036 & 1.036 & 1.036 & 1.036 & 1.036 & 1.036 & 1.036 \\
0.8 & 0.997 & 0.997 & 1.004 & 1.009 & 1.009 & 1.012 & 1.012 & 1.012 & 1.024 & 1.026 \\
0.9 & 1.002 & 1.002 & 1.012 & 1.036 & 1.049 & 1.049 & 1.049 & 1.061 & 1.061 & 1.061 \\
1.0 & 1.049 & 1.073 & 1.098 & 1.110 & 1.123 & 1.140 & 1.160 & 1.165 & 1.184 & 1.197 \\
\hline 2.25
\end{tabular}

\subsection{D Modeling of the 300t fishery administration vessel.}

Three-dimensional modeling is constructed accurately to calculate added water mass of the $300 t$ fishery administration vessel. The main technical parameters are showed in table 4 . As the structure is 
complex, three-dimensional model of the hull structure is established in Pro/E according to the design paper. 3D geometric model of the 300t fishery administration vessel is showed in Fig.1

Table 4 Main parameters of the $300 t$ fishery administration vessel

\begin{tabular}{ccc}
\hline Parameter & Size & Unit \\
\hline Ship length & 49.9 & metre \\
Length between perpendiculars & 47.0 & metre \\
Molded breadth & 7.6 & metre \\
Moulded depth & 4.3 & metre \\
Frame space & 0.5 & metre \\
Mean draught of no-load condition & 2.1 & metre \\
Ligth displacement & 269.2 & ton \\
Full load displacement & 340.1 & ton \\
\hline
\end{tabular}
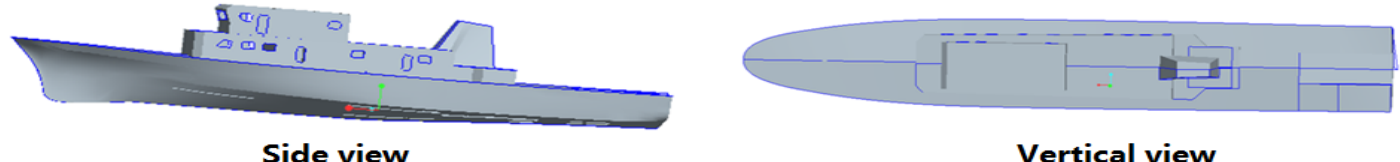

Vertical view

Fig. 1 Three-dimensional geometric model of the 300t fishery administration vessel

\section{Calculation of the added water mass}

Formula 1 and formula 2 are used to calculate the added water mass per unit length of each section. After calculating the added water mass of 21 segments, the average value of the added mass of the adjacent section is calculated. Finally, the added water mass of vertical and horizontal vibration are calculated. Reference ship vibration control guide of CCS, detailed calculation process of the added water mass of $1^{\text {st }}$ vertical vibration is showed in Table 5

Table 5. Calculation of added water mass of 1 st vertical vibration

\begin{tabular}{ccccccc}
\hline $\begin{array}{c}\text { The vessel } \\
\text { segmented } \\
\text { number }\end{array}$ & $\begin{array}{c}\text { Ratio of half } \\
\text { width of } \\
\text { waterline and } \\
\text { sea gauge } \\
\text { (b/d) }\end{array}$ & $\begin{array}{c}\text { Area } \\
\text { coefficient of } \\
\text { rated } \\
\text { section }(\beta)\end{array}$ & $\begin{array}{c}\text { Added mass } \\
\text { coefficient of } \\
\text { vertical } \\
\text { vibration }(\mathrm{Cv})\end{array}$ & $\begin{array}{c}\text { 3D flow } \\
\text { correction } \\
\text { factors } \\
(\mathrm{Kv} 1)\end{array}$ & $\begin{array}{c}\text { Added water } \\
\text { mass in rated } \\
\text { section(t/m) }\end{array}$ & $\begin{array}{c}\text { Added water } \\
\text { mass of } \\
\text { vessel } \\
\text { segmented } \\
(\mathrm{t})\end{array}$ \\
\hline 0 & 1.096 & 0.176 & 0.750 & & 4.373 & - \\
1 & 1.612 & 0.257 & 0.760 & & 9.584 & 16.399 \\
2 & 1.641 & 0.310 & 0.770 & & 10.061 & 23.084 \\
3 & 1.668 & 0.356 & 0.781 & & 10.542 & 24.209 \\
4 & 1.695 & 0.405 & 0.790 & & 11.011 & 25.325 \\
5 & 1.719 & 0.452 & 0.805 & & 11.545 & 26.503 \\
6 & 1.742 & 0.501 & 0.821 & & 12.090 & 27.772 \\
7 & 1.760 & 0.549 & 0.825 & & 12.408 & 28.785 \\
8 & 1.771 & 0.593 & 0.875 & & 13.264 & 30.235 \\
9 & 1.767 & 0.617 & 0.875 & 0.748 & 12.622 & 30.416 \\
10 & 1.729 & 0.615 & 0.870 & & 11.475 & 28.314 \\
11 & 1.653 & 0.599 & 0.865 & & 9.980 & 25.210 \\
12 & 1.547 & 0.584 & 0.859 & & 7.979 & 21.102 \\
13 & 1.411 & 0.569 & 0.826 & & 6.079 & 16.518 \\
14 & 1.239 & 0.557 & 0.816 & & 4.139 & 12.006 \\
15 & 1.042 & 0.500 & 0.785 & & 2.576 & 7.890 \\
16 & 0.828 & 0.500 & 0.774 & & 1.468 & 4.752 \\
17 & 0.622 & 0.552 & 0.783 & & 0.639 & 2.476 \\
18 & 0.409 & 0.575 & 0.788 & & 0.130 & 0.904 \\
19 & 0.193 & 0.551 & 0.720 & & 0.000 & 0.152 \\
20 & 0.000 & 0.00 & 0.000 & & & 383.292 \\
\hline Mv1 & & & & & & \\
\hline
\end{tabular}


Table 6. Added water mass for no load

\begin{tabular}{ccc}
\hline Order & Added water mass of vertical vibration(ton) & Added water mass of horizontal vibration(ton) \\
\hline 1 & 383.3 & 340.1 \\
2 & 347.4 & 330.8 \\
3 & 314.6 & 323.1 \\
\hline
\end{tabular}

Based on the above method, the added water mass for no load of first three order vertical and horizontal vibration are calculated and showed in Table 6 . The added water mass for full load of first three order vertical and horizontal vibration are showed in Table 7.

Table 7. Added water mass for full load

\begin{tabular}{ccc}
\hline Order & Added water mass of vertical vibration(ton) & Added water mass of horizontal vibration(ton) \\
\hline 1 & 412.1 & 421.8 \\
2 & 373.5 & 410.4 \\
3 & 338.3 & 400.7 \\
\hline
\end{tabular}

\section{Summary}

The main conclusions drawn from the results of this study are listed as follows:

(1)The added water mass of full load is greater than the no-load condition.

(2) Under the condition of no load, the added mass of vertical vibration is greater than horizontal vibration. Under the condition of full load, the added mass of horizontal vibration is greater.

(3)The added water mass for no-load is greater than light displacement; the added water mass for full load is greater than Full load displacement

\section{References}

[1]. Wu J S, Hsieh M. An experimental method for determining the frequency-dependent added mass and added mass moment of inertia for a floating body in heave and pitch motions. Ocean Engineering. Vol. 28(2001) No. 4, p. 417-438.

[2]. Zhu J, Lin Z, Liu Q, et al. Calculation of the Added Mass of a Liquid Tank's Bulkheads. Journal of Marine Science and Application. Vol. 13 (2014) No. 1, p. 41-48.

[3]. Clarke, D. Calculation of the added mass of circular cylinders in shallow water. Ocean Engineering. Vol. 28 (2001) No. 9, p. 1265-1294.

[4]. Rahman M, Bhatta D. Evaluation of added mass and damping coefficient of an oscillating circular cylinder. Applied Mathematical Modelling. Vol. 17(1993) No. 2, p. 70-79.

[5]. CCS. Ship vibration control guide. China Communications Press, 2012, p. 149-165.

[6]. He X J, Huang Y, Lan M, et al. A Basic Computation Model of Added Mass on Ship Section with Green Function. Applied Mechanics \& Materials, Vol. 556-562(2014), p. 3678-3681. 